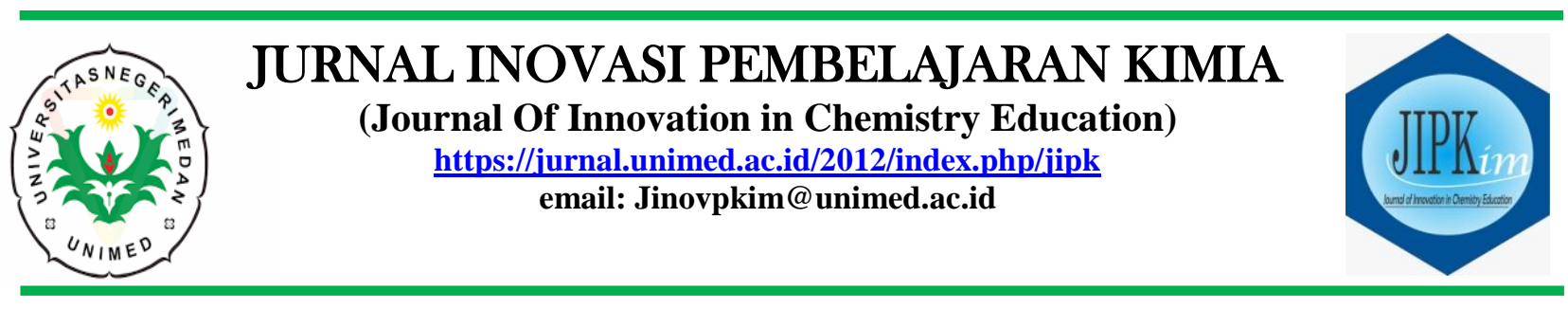

$\begin{array}{ll}\text { Masuk } & : \text { 2 Agustus } 2020 \\ \text { Revisi } & : \text { 16 September 2020 } \\ \text { Diterima } & : \text { 30 Oktober 2020 } \\ \text { Diterbitkan } & : \text { 30 Oktober } 2020 \\ \text { Halaman } & : 64-70\end{array}$

\title{
Pembelajaran PBL Menggunakan Bahan Ajar Terintegrasi Nilai Spiritual untuk Meningkatkan Hasil Belajar dan Sikap Spiritual
}

\author{
Aisah Harahap ${ }^{1 *}$, Ayi Darmana ${ }^{1}$ \\ ${ }^{1}$ Program Studi Pendidikan Kimia, Universitas Negeri Medan, Medan \\ *Alamat Korespondensi: aisyahharahap73@gmail.com
}

\begin{abstract}
This study aims to determine the differences in student learning outcomes taught with integrated spiritual value teaching materials and textbooks of SMA / MA, differences in students 'spiritual attitudes before and after being taught with integrated spiritual value teaching materials and the relationship between learning outcomes and students' spiritual attitudes. The research method is a quasi-experimental method. Sampling using random sampling technique so that the score is 2 classes. The instrument used was a test instrument and a questionnaire using Cronbach's Product Moment and Alpha test. Data analysis in the form of Independent Sample T-Test, Paired Sample T-Test and Correlation using IBM SPSS Statistics 22 for Windows. The results showed a sign price (2-tailed) for an increase in learning outcomes is 0,000, an increase in spiritual attitudes is 0,000 and the relationship between learning outcomes and spiritual attitudes is 0.008 . From the results of the study it can be concluded that there are differences in student learning outcomes taught using integrated spiritual value teaching materials and SMA / MA textbooks, there are differences in students' spiritual attitudes before and after being taught with integrated spiritual value teaching materials and there is a relationship between spiritual attitudes and learning outcomes.
\end{abstract}

Keywords: Problem Based Learning, Learning Outcomes, Islamic Values, Teaching Materials

\section{PENDAHULUAN}

Pendidikan Nasional berfungsi untuk mengembangkan kemampuan dan membentuk watak serta peradaban bangsa yang bermartabat dalam rangka mencerdaskan kehidupan bertujuan untuk menstimulus berkembangnya potensi peserta didik agar menjadi manusia yang beriman dan bertaqwa kepada Tuhan Yang Maha Esa, berakhlak mulia, sehat, berilmu, cakap kreatif, mandiri dan menjadi warga negara yang demokratis serta bertanggungjawab (UU,
2003). Selama ini penyelenggaraan pendidikan di Indonesia biasanya hanya berorientasi pada tujuan untuk menjadikan peserta didik menjadi manusia yang berilmu terutama dalam pengetahuan kognitifnya, sedangkan nilai-nilai spiritual (KI-1) peserta didik tidak mendapat perhatian dari pendidik. Menurut (Darmansyah, 2003), sikap spiritual belum mendapatkan proporsi yang memadai dalam proses pembelajaran. Potensi-potensi peserta didik belum terintegrasi secara optimal dalam pembelajaran, sehingga terjadi 
pendangkalan nilai karakter di kalangan anak remaja dewasa ini. Danah Zohar dan Ian Marshall dalamSafaria (2007) menjelaskan, kecerdasan spiritual sebagai "is the necessary for the effective functioning of both $I Q$ and EQ. It our ultimate intelligence". Mereka berdua menjelaskan bahwa tanpa kecerdasan spiritual (SQ), maka IQ dan EQ tidak akan berjalan dengan efektif dan optimal. Kecerdasan Spiritual menurut mereka merupakan kecerdasan tertinggi pada manusia, yang melingkupi seluruh kecerdasan yang ada pada manusia.

Salah satu cara untuk membentuk manusia yang beriman dan bertaqwa bisa dilakukan dengan menghadirkan aspek spiritual keagamaan ke dalam materi ajar kimia, karena bahan ajar yang ada saat ini cenderung hanya mengembangkan kompetensi pengetahuan dan keterampilan, tetapi mengabaikan ketercapaian kompetensi sikap spiritual dan kompetensi sikap sosial (Fitriani \& Darmana, 2016). Abdul Majid (2006) mengemukakan bahwa tujuan dari penyusunan bahan ajar adalah: (1)membantu siswa dalam mempelajari sesuatu; (2)memudahkan guru dalam melaksanakan pembelajaran; (3)agar kegiatan pembelajaran menjadi lebih menarik; dan (4)menyediakan berbagai jenis bahan ajar (Prastowo, 2011).

Pembelajaran kimia di sekolah dengan hanya memperhatikan dari sisi ilmiah semata tidak akan menjadikan sarana bagi siswa untuk memiliki akhlak yang mulia, terlebih lagi jika berharap untuk membentuk siswa yang beriman dan bertaqwa sesuai dengan tujuan pendidikan nasional. Menghadirkan nilai-nilai agama dalam sains yang ilmiah merupakan suatu cara yang sangat baik. Cara ini dapat memberikan pemahaman yang komprehensif dari sudut ilmiah dan spiritual (Darmana, n.d.). Karena dalam ilmu kimia banyak terdapat materi-materi pelajaran yang mengandung nilai-nilai keindahan dan keteraturan yang pada akhirnya mengarah kepada peng-Agungan sang pencipta serta jika dapat menggali lebih dalam lagi hakikat makna dibalik peristiwa-peristiwa kimia tersebut, maka akan diperoleh banyak sekali nilai-nilai religiusnya yang sangat diperlukan oleh para siswa sebagai bekal hidup di dunia (Djudin, 2011).

Menurut (Darmana, n.d.), bahwa menghadirkan aspek spiritual dalam materi ajar tidak akan mengurangi kualitas tingkat ilmiah dari kimia itu sendiri, bahkan merupakan upaya yang benar-benar tepat karena dapat mengembalikan pemahaman siswa bahwa segala fenomena termasuk penemuan-penemuan sains yang telah ditemukan merupakan takdir yang telah ditetapkan oleh Tuhan tentang kejadiannya. Selain itu, integrasi nilai spiritual ke dalam bahan ajar bisa membantu guru untuk menambah pemahaman spiritual siswa, karena menurut penelitian (Darmana et al., 2013) dan (A'ini, 2014) bahwa tingkat kecerdasan spiritual guru kimia masih tergolong kategori cukup.

Agar hasil belajar siswa dapat tumbuh dan berkembang secara baik, guru perlu meningkatkan hasil belajar siswa dalam pembelajaran dengan menerapkan model pembelajaran. Salah satunya yaitu model pembelajaran Problem Based Learning yang sesuai dengan kurikulum 2013. Menurut Arends, Problem Based Learning (PBL) merupakan suatu pendekatan pembelajaran dimana siswa dihadapkan pada masalah autentik (nyata) sehingga diharapkan mereka dapat menyusun pengetahuannya sendiri, menumbuh kembangkan keterampilan tingkat tinggi dan inkuiri, memandirikan siswa, dan meningkatkan kepercayaan dirinya. Problem Based Learning atau Pembelajaran Berbasis Masalah merupakan inovasi dalam pembelajaran karena dalam PBL kemampuan berpikir siswa betul-betul dioptimalisasikan melalui proses kerja kelompok atau tim yang sistematis, sehingga siswa dapat memberdayakan, mengasah, menguji, dan mengembangkan kemampuan berpikirnya secara berkesinambungan (Nurdiansyah, 2016).

Pelaksanaan model pembelajaran Problem Based Learning terdiridari 5 fase utama yaitu orientasi siswa pada masalah, 
mengorganisasi siswa untuk belajar, membimbing pengalaman individu/ kelompok, mengembangkan dan menyajikan hasil karya, menganalisis dan mengevaluasi proses pemecahan masalah. Fase-fase tersebut merujuk pada tahapan tahapan yang dilakukan dalam kegiatan pembelajaran dengan PBL. Problem Based Learning dapat menghasilkan generasi penerus bangsa yang produktif, kreatif, inovatif dan berkarkter (Trianto,2010).

Ada beberapa penelitian-penelitian yang berupaya untuk mendekatkan pembelajaran sains dengan nilai-nilai spiritual seperti ((Darmana, n.d.); (Darmana, 2014); (Sundari \& Darmana, 2013); (Fitriani \& Darmana, 2016); (Putriany, n.d.); (Handayani, 2018); (Noor, n.d.); (Damanik, n.d.); (Okmarisa et al., 2016)). Penelitian sebelumnya yang dilakukan (Okmarisa et al., 2016) tentang Implementasi Bahan Ajar Kimia Terintegrasi Nilai Spiritual dengan Model Pembelajaran Problem Based Learning (PBL) Berorientasi Kolaboratif untuk Meningkatkan Hasil Belajar Siswa yang memberikan hasil terdapat perbedaan yang signifikan hasil belajar yang diajar menggunakan bahan ajar kimia terintegrasi nilai spiritual dengan hasil belajar siswa yang diajar menggunakan buku ajar kimia dan dapat menumbuhkembangkan nilai spiritual pada siswa.

Penelitian ini dilakukan untuk mengetahui perbedaan hasil belajar siswa yang diajarkan dengan menggunakan bahan ajar kimia terintegrasi nilai spiritual dan buku paket reguler,perbedaan sikap spiritual siswa sebelum dan sesudah diajarkan menggunakan bahan ajar kimia terintegrasi nilai spritual dan hubungan sikap spiritual dengan prestasi belajar siswa.

\section{METODE}

Penelitian ini menggunakan metode quasi eksperimen, dilakukan di SMA Cerdas Murni Medan pada semester ganjil Tahun Ajaran 2019/2020 dengan materi Laju Reaksi. Populasi dalam penelitian adalah seluruh siswa kelas XI MIA di SMA Cerdas Murni
Medan. Pemilihan sampel dilakukan dengan teknik random sampling dan diperoleh sampel sebanyak 2 kelas.

\begin{tabular}{c|c|c|c}
\hline Kelompok & Pre-Test & Perlakuan & Post-Test \\
\hline Eksperimen I & $\mathrm{T}_{1}$ & $\mathrm{X}$ & $\mathrm{T}_{2}$ \\
\hline Eksperimen II & $\mathrm{T}_{1}$ & $\mathrm{Y}$ & $\mathrm{T}_{2}$ \\
\hline
\end{tabular}

Tabel 1. Rancangan Penelitian

Instrumen penelitian yang digunakan yaitu tes objektif dan angket dengan uji validitas dan reliabilitas menggunakan program IBM SPSS Statistics 22 for Windows.

Analisa data dilakukan dengan bantuan program IBM SPSS Statistics 22 for Windows. Teknik analisa data dilakukan untuk melihat peningkatan hasil belajar menggunakan rumus N-Gain ternormalisasi. Selanjutnya dilakukan uji Independent Sample T-Test, Paired Sample T-Test dan Correlation dengan nilai sign $<0,05$. Sebelum menggunakan teknik analisa ini dilakukan uji prasyarat data yang harus dipenuhi yaitu normalitas dan homogenitas. Uji normalitas menggunakan program IBM SPSS Statistics 22 for Windows dengan pendekatan Kolmogrov-Smirnovdan homogen menggunakan pendekatan Levene Statistic Test.

\section{HASIL DAN PEMBAHASAN}

\section{PeningkatanHasilBelajar}

Secara keseluruhan terdapat perbedaan hasil belajar antara kelas eksperimen I dan kelas eksperimen II yang dapat dilihat pada gambar 2 yaitu nilai $\mathrm{N}$ gain yang diperoleh pada peningkatan hasil belajar. Pada kelas eksperimen I yang diajarkan dengan menggunakan bahan ajar kimia terintegrasi nilai spiritual memiliki NGain sebesar 0,4354 dengan persen peningkatan hasil belajar sebesar $43 \%$ dan pada kelas eksperimen II yang diajarkan dengan menggunakan bahan ajar buku paket SMA/MA memiliki N-gain sebesar 0,1245 dengan persen peningkatan hasil belajar $12 \%$ pada materi Laju Reaksi kelas XI MIA semester ganjil di SMA Cedas Murni Medan. 


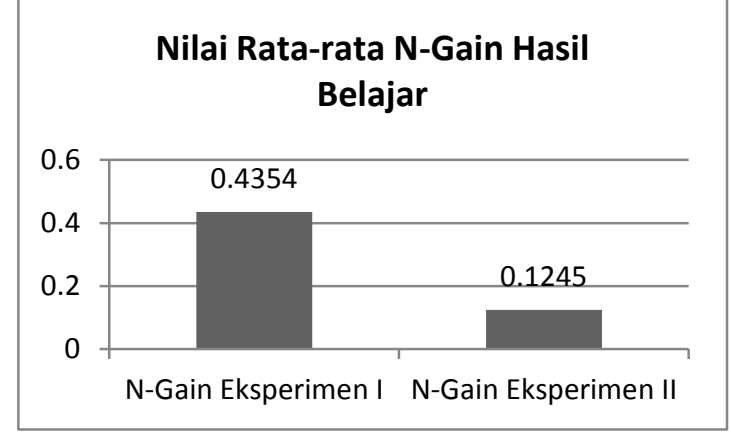

Gambar 2. Perbandingan Nilai Rata-rata N GainHasil belajar

Berdasarkan hasil uji hipotesis, melalui pengujian data dengan program $I B M$ SPSS Statistics 22 for windows diketahui bahwa bahan ajar kimia terintegrasi nilai spiritual berpengaruh terhadap hasil belajar siswa. Hasil belajar siswa yang diajarkan dengan bahan ajar kimia terintegrasi nilai spiritual lebih tinggi daripada hasil belajar siswa yang diajarkan dengan menggunakan bahan ajar buku paket SMA/MA dengan nilai Sign (Sign. 2-tailed) $<0,05$ (tingkat kesalahan $5 \%$, tingkat kepercayaan $95 \%$ ) yaitu 0,000 . Maka diperoleh kesimpulan terdapat perbedaan hasil belajar siswa yang diajarkan menggunakan bahan ajar kimia terintegrasi nilai spiritual dengan bahan ajar buku paket SMA/MA.

Adanya perbedaan hasil belajar siswa yang diajarkan menggunakan bahan ajar kimia terintegrasi nilai spiritual dengan bahan ajar buku paket SMA/MA dipengaruhi oleh bahan ajar yang digunakan karena bahan ajar terintegrasi nilai spiritual dapat mendorong siswa membentuk sikap positif terhadap kimia dengan menyadari keteraturan dan keindahan alam serta mengagungkan kebesaran Tuhan Yang Maha Esa. Hal ini sesuai dengan pendapat (Saputro, 2006) yang menyatakan bahwa siswa tertarik untuk mempelajari kimia lebih mendalam karena ilmu kimia bukanlah kumpulan rumus-rumus dan persamaan reaksi yang harus dihapal untuk kemudian dilupakan setelah lulus sekolah, melainkan ilmu yang mempelajari keindahan keteraturan hukumhukum ilahi di alam semesta. Dan juga siswa yang memiliki kecerdasan spiritual yang tinggi akan cenderung bertanggungjawab dengan pekerjaannya. Hal inilah yang membuat hasil belajar siswa yang diajarkan dengan bahan ajar kimia terintegrasi nilai spiritual lebih tinggi dibandingkan yang diajarkan dengan buku paket SMA/MA.

Banyak studi yang mengisyaratkan pentingnya pengintegrasian aspek spiritual dalam pembelajaran, diantaranya (Darmana et al., 2013) yang berpendapat mengintegrasikan nilai-nilai tauhid dalam materi ajar tidak akan mengurangi kualitas tingkat ilmiah dari sains itu sendiri, bahkan merupakan upaya yang tepat karena berarti mengembalikan bersatunya antara syariat dan hakikat. Hal ini senada dengan yang dikatakan Rahmania (2018) bahwa bahan ajar yang telah diintegrasikan dengan nilai-nilai spiritual yang dihubungkan dalam kehidupan dan materi kimia akan mendorong sikap positif bukan hanya pada kimia tapi juga pada pribadi siswa berupa rasa syukur, beriman, bertaqwa dan ikhlas melalui kesadaran bahwa adanya hubungan antara kimia dan keteraturan juga keindahan ciptaan Tuhan

\section{Perbedaan Sikap Spiritual Menggunakan Bahan Ajar Kimia Terintegrasi Nilai Spiritual}

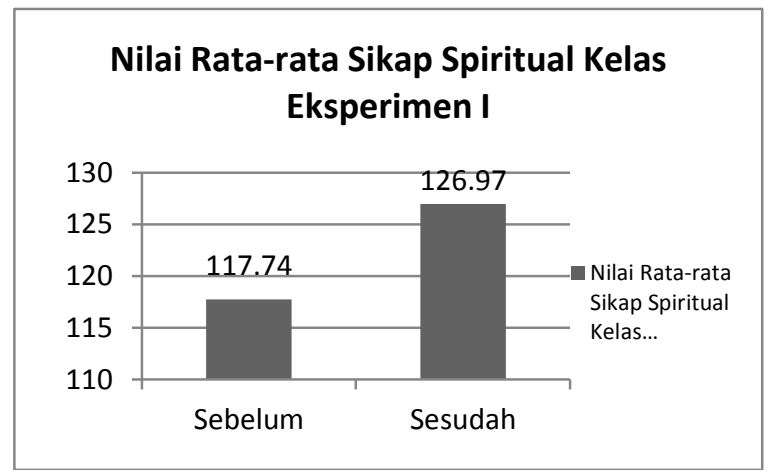

Gambar 2. Perbandingan Nilai RatarataSikapSpiritual Kelas Eksperimen I

Dalam penelitian ini pengintegrasian nilai-nilai spiritual dilakukan dengan menyisipkan nilai-nilai spiritual ke dalam bahan ajar yang disesuaikan dengan materi laju reaksi. Dari hasil penelitian (Gambar 2) menunjukkan telah terjadi peningkatan sikap spiritual siswa. Hal ini dapat dilihat pada gambar 2 yaitu peningkatan sikap spiritual sebelum dan sesudah diberi perlakuan berdasarkan angket penilaian diri siswa dari 117,74 menjadi 126,97 dengan N-Gain yang 
diperoleh 26,78\%. Pada pengujian data dengan program IBM SPSS Statistics 22 for Windows diperoleh hasil untuk sikap spiritual siswa pada kelas eksperimen I dengan nilai sign. (2-tailed) < 0,05 (tingkat kesalahan 5\%) yaitu 0,000 . Artinya terdapat pebedaan sikap spiritual siswa sebelum dan sesudah diberi perlakuan menggunakan bahan ajar kimia terintegrasi nilai spiritual.

Siswa siswa di SMA Cerdas Murni Medan pada dasarnya sudah memiliki spiritual yang baik karena sekolah ini merupakan sekolah yang berbasis islami yang telah mengintegrasikan nilai spiritual kepada peserta didik melalui peraturan-peraturan baik secara tertulis maupun tidak tertulis. Diantara sikap spiritual adalah sebelum pelajaran dimulai berdoa terlebih dahulu dan dilanjutkan membaca ayat suci Al-Qur'an. Sehingga siswa terbiasa berdoa ketika hendak melakukan apapun. Hanya saja nilai spiritual belum diintegrasikan dalam setiap materi pada pembelajaran dari setiap mata pelajaran.Untuk mengintegrasikan nilai-nilai spiritual dapat dilakukan dengan menyisipkan nilai-nilai spiritual ke dalam bahan ajar yang disesuaikan dengan materi laju reaksi sehingga terdapat perbedaan sikap spiritual siswa sebelum dan sesudah diberi perlakuan menggunakan bahan ajar kimia terintegrasi nilai spiritual.

Hal ini karena bahan ajar yang telah dikembangkan dilengkapi dengan unsurunsur religius dan memberikan energi positif kepada siswa. Pembelajaran menggunakan bahan ajar kimia terintegrasi nilai spiritual memberikan respon dan tanggungjawab berdasarkan kadar kecerdasan spiritual yang dimiliki masing-masing siswa yang efektif meningkatkan hasil belajar dan kecerdasan spiritual sehingga siswa tidak hanya menekankan segi-segi pengetahuan kognitif intelektual saja tetapi juga menumbuhkan segi-segi kualitas psikomotorik dan kesadaran spiritual yang reflektif dalam kehidupan sehari-hari untuk mendidik hati dan budi pekerti siswa. Hal ini sesuai dengan hasil penelitian (Saputro, 2006) yang menyatakan bahwa pengintegrasian nilai-nilai religius yang bersumber dari ayat-ayat Al-Qur'an dalam buku pelajaran imia dapat menanamkan pendidikan islami (karakter insan mulia) kepada siswa. Hal senada juga diungkapkan (Djudin, 2011) yang menyatakan bahwa menyisipkan nilai-nilai agama dalam pelajaran sains merupakan ikhtiar nyata untuk menwujudkan tujuan pembelajara IPA agar siswa mengagungkan dan mengimani Sang Pencipta.

\section{Hubungan Sikap Spiritual terhadap Hasil Belajar}

Hubungan sikap spiritual dengan hasil belajar dilakukan dengan analisa menggunakan program IBM SPSS Statistics 22 for Windows. Dari hasil pengujian diperoleh nilai sign. (2-tailed) $<0,05$ (tingkat kesalahan5\%) yaitu 0,008 sehingga dapat disimpulkan terdapat hubungan antara sikap spiritual dan hasil belajar siswa dengan menggunakan bahan ajar terintegrasi nilai spiritual. Besarnya hubungan nilai spiritual terhadap peningkatan hasil belajar siswa dapat dilihat dari Pearson Correlation sebesar 0,466 . Jika dilihat dari interval hubungan korelasi maka termasuk rentang korelasi cukup.

Dari hasil penelitian tersebut dapat disimpulkan bahwa, siswa dengan hasil belajar yang baik cenderung memiliki nilai spiritual yang tinggi dan siswa dengan hasil belajar yang rendah memiliki nilai spiritual yang rendah. Hal ini senada dengan yang dikatakan (Jumini, 2015) bahwa ilmu agama dapat dijadikan penyeimbang dari ilmu sains, karena jika ilmu sains tidak diseimbangkan dengan ilmu agama maka akan menghasilkan kemajuan secara fisik tetapi kering dalam aspek spiritual. Kombinasi sains dan agama merupakan kombinasi konsep yang tepat untuk memahami alam (Marsonet, n.d.).

\section{KESIMPULAN}

Berdasarkan hasil dan pembahasan, diperoleh beberapa kesimpulan yaitu terdapat perbedaan hasil belajar antara siswa yang diajarkan dengan menggunakan bahan ajar kimia terintegrasi nilai spiritual dan 
buku paket SMA/MA, terdapat perbedaan sikap spiritual siswa sebelum dan sesudah diajarkan dengan menggunakan bahan ajar kimia terintegrasi nilai spiritual dan terdapat hubungan sikap dengan peningkatan hasil belajar.

\section{DAFTAR PUSTAKA}

A'ini, Q., (2014), Analisis Permasalahan Guru dalam Mengimplementasikan Kompetensi Spiritual setelah Diterapkan Kurikulum 2013 pada Pembelajaran Matematika, Naskah Publikasi, Surakarta.

Amir, T., (2009), Inovasi Pendidikan melalui Problem Based Learning, Kencana Prenada Media Group, Jakarta.

Darmana, A., (2012), Internalisasi Nilai Tauhid dalam Pembelajaran Sains, Jurnal Pendidikan Islam, 27(1): 66-84

Darmana, A., (2013), Internalisasi Nilai Nilai Agama Islam dalam Pembelajaran Kimia Di SMA Plus Al Azhar Medan Sumatera Utara, Makalah pada Seminar Nasional IPA IV UNNES, Semarang.

Darmana, A., (2014), Internalisasi Nilai Tauhid pada Pembelajaran Kimia untuk Menigkatkan Kemampuan Siswa SMA dalam Memahami NilaiNilai Agama dan Kimia, Disertasi, Universitas Pendidikan Indonesia.

Darmana, A., dan Batubara, M., (2016), Kelayakan Bahan Ajar Kimia-Tauhid Berdasarkan Kriteria Badan Standart Nasional Pendidikan (BNSP) dan Respon Siswa, Prosiding Seminar Nasional Kimia dan Pendidikan Kimia, Medan.

Darmana, A., dkk, (2013), Pandangan Siswa terhadap Internalisasi Nilai Tauhid Melalui Materi Termokimia, Prosiding Semirata FMIPA UNILA, Lampung.

Darmana, A., dkk, (2014), Pandangan Siswa terhadap Internalisasi Nilai Tauhid melalui Materi Kimia serta Perlunya dalam Pelajaran IPA, Jurnal Penelitian Bidang Pendidikan, 19(2): 87-97.
Damanik, M. F., (2018), Efektivitas Pembelajaran Menggunakan Modul Kimia Terintegrasi Nilai-Nilai Islami pada Pokok Bahasan Hidrolisis Garam untuk Meningkatkan Hasil Belajar Siswa Kelas XI MAN 1 Medan, Skripsi, Universitas Negeri Medan, Medan.

Darmansyah, (2014), Teknik Penilaian Sikap Spiritual dan Sosial dalam Pendidikan Karakter di Sekolah Dasar 08 Gurau Gdang Nanggalo, Jurnal Al Ta'lim, 21(2): 10-17.

Djudin, T., (2011), Menyisipkan Nilai-Nilai Agama dalam Pembelajaran Sains: Upaya Alternatif Memagari Aqidah Siswa, Jurnal Khatulistiwa, 1(2): 151160.

Fitriana, F., Mahmud dan Darmana, A., (2016), Pengembangan dan Standarisasi Bahan Ajar Kimia Terintegrasi Nilai-Nilai Spiritual untuk Kelas XI SMA/MA Semester 1 Berdasarkan Badan Standar Nasional Pendidikan, Jurnal Pendidikan Kimia, 8(1): 12-18.

Hamalik, O., (2007), Proses Belajar Mengajar, PT Bumi Aksara, Jakarta.

Handayani, H., (2018), Implementasi Bahan Ajar Kimia Hidrokarbon dan Minyak Bumi Terintegrasi Nilai Agama untuk Meningkatkan Pengetahuan dan Nilai Spiritual Siswa, Tesis, Universitas Negeri Medan, Medan.

Jumini, S., dan Wahyudi, (2015), Konsep Vektor dan Nilai-Nilai Pendidikan Spiritual di dalamnya, Jurnal PPKM, $1: 1-10$.

Lestari, I., (2013), Pengembangan Bahan Ajar Berbasis Kompetensi, Akademia, Padang.

Marsonet, M., (2012), Science and Religion as Conceptual Schemes, Academicus, 5: 17-25.

Noor, M. F., (2018), Efektivitas Pembelajaran Menggunakan Bahan Ajar Kimia Berbasis Nilai-Nilai Spiritual untuk Meningkatkan Hasil Belajar Siswa Kelas X pada Materi Reaksi Redoks, 
Skripsi, Universitas Negeri Medan, Medan.

Nurdiansyah dan Fahyuni, E. F., (2016), Inovasi Model Pembelajaran sesuai Kurikulum 2013, Nizamia Learning Center, Sidoarjo.

Pemerintah Republik Indonesia, (2003), Undang-Undang Sistem Pendidikan Nasional No 20 Tahun 2003, Presiden Republik Indonesia, Jakarta.

Prastowo, A., (2011), Panduan Kreatif membuat Bahan Ajar Inovatif, DIVA Press, Yogyakarta.

Oksamarisa, H., Darmana, A., dan Suyanti, R. D., (2016), Implementasi Bahan Ajar Kimia Terintegrasi Nilai Spiritual dengan Model Pembelajaran Problem Based Learning (PBL) Berorientasi Kolaboratif untuk Meningkatkan Hasil Belajar Siswa, Jurnal Pendidikan Kimia, 8(2): 130-135.

Putriany, (2008), Implementasi Bahan Ajar Kimia Terintegrasi Nilai-Nilai Islami pada Pokok Bahasan Hidrokarbon dengan Model Problem Based Learning (PBL) Untuk Meningkatkan Hasil Belajar Siswa Kelas XI MAN 1 Aceh Tenggara, Skripsi, Universitas Negeri Medan, Medan.

Saputro, A.N.C., (2011), Pengintegrasi NilaiNilai Religius dalam Buku Pelajaran Kimia sebagai Metode Alternatif Membentuk Karakter Insan Mulia Pada Siswa, Seminar Nasional VIII Pendidikan Biologi, FMIPA FKIP Universitas Sebelas Maret, Surakarta.

Syah, M., (2008), Psikologi Pendidikan, PT Remaja Roesda Karya, Bandung.

Trianto, (2010), Mendesain Model Pembelajaran Inovatif-Progresif, Kencana, Jakarta.

Zega, I. S., dan Darmana, A., (2019), Implementasi Bahan Ajar Hidrolisis Garam Terintegrasi Nilai-Nilai Islami dengan Model Problem Based Learning untuk Meningkatkan Hasil Belajar Siswa Ditinjau dari Minat Belajar Siswa, Jurnal Inovasi Pembelajaran Kimia, 1(2): 15-24. 